\title{
The oxidative stress theory of aging: embattled or invincible? Insights from non-traditional model organisms
}

\author{
Rochelle Buffenstein • Yael H. Edrey • Ting Yang • \\ James Mele
}

Received: 16 April 2008 / Accepted: 22 April 2008 / Published online: 14 June 2008

(C) American Aging Association 2008

\begin{abstract}
Reactive oxygen species (ROS), inevitable byproducts of aerobic metabolism, are known to cause oxidative damage to cells and molecules. This, in turn, is widely accepted as a pivotal determinant of both lifespan and health span. While studies in a wide range of species support the role of ROS in many agerelated diseases, its role in aging per se is questioned. Comparative data from a wide range of endotherms offer equivocal support for this theory, with many exceptions and inconclusive findings as to whether or not oxidative stress is either a correlate or a determinant of maximum species lifespan. Available data do not support the premise that metabolic rate and in vivo ROS production are determinants of lifespan, or that superior antioxidant defense contributes to species longevity. Rather, published studies often show either a negative associate or lack of correlation with species longevity. Furthermore, many long-living species such as birds, bats and mole-rats exhibit high levels of oxidative damage even at young
\end{abstract}

R. Buffenstein $(\bowtie) \cdot J$. Mele

Barshop Institute for Aging and Longevity Studies and Department of Physiology,

University of Texas Health Science Center at San Antonio, 15355 Lambda Drive, STCBM \#2.2,

San Antonio, TX 78245, USA

e-mail: Buffenstein@UTHSCSA.edu

Y. H. Edrey • T. Yang

Graduate School and The City College of New York,

City University of New York,

New York, NY 10031, USA ages. Similarly genetic manipulations altering expression of key antioxidants do not necessarily show an impact on lifespan, even though oxidative damage levels may be affected. While it is possible that these multiple exceptions to straightforward predictions of the free radical theory of aging all reflect speciesspecific, "private" mechanisms of aging, the preponderance of contrary data nevertheless present a challenge to this august theory. Therefore, contrary to accepted dogma, the role of oxidative stress as a determinant of longevity is still open to question.

Keywords Aging $\cdot$ Bats · Birds · Comparative biology of aging $\cdot$ Lifespan $\cdot$ Mole-rats $\cdot$ Oxidative stress

$\begin{array}{ll}\text { Abbreviations } \\ \text { ATP } & \text { Adenosine Triphosphate } \\ \text { CAT } & \text { Catalase } \\ \text { Cu/Zn SOD } & \text { Cu/Zn superoxide dismutase } \\ \text { DNA } & \text { Deoxyribonucleic Acid } \\ \text { GSH/ } & \begin{array}{l}\text { Reduced glutathione/oxidized } \\ \text { glutathione }\end{array} \\ \text { GSSG } & \text { Mitogen-activated protein kinase } \\ \text { MAPK } & \text { Maximum species lifespan } \\ \text { NAD } & \text { Oxidized nicotinic adenine } \\ & \text { dinucleotide } \\ \text { NADH } & \text { Reduced nicotinic adenine dinucleotide } \\ \text { NMR } & \text { Naked mole-rat } \\ \text { ROS } & \text { Reactive oxygen species } \\ \text { SOD } & \text { Superoxide dismutase } \\ \text { TNF } & \text { Tumor necrosis factor }\end{array}$




\section{Introduction}

Aging, generally regarded as an endogenous, progressive, irreversible, and deleterious process (Strehler 1962), remains one of the most poorly understood biological phenomena. In spite of considerable research effort, the endogenous causes of aging remain elusive, and it is still not known why certain mammals (namely humans, mole-rats and bats) age more slowly than predicted by body size compared to other species. Aging research predominantly focuses on two competing concepts. Firstly, certain genes control lifespan primarily through modulation of hormone secretions and their signalling pathways (Bartke 2008; Finch and Ruvkun 2001). The second theory is based upon the hypothesis that accumulation of oxidative damage is responsible for the progressive functional deterioration with advancing years (Harman 1956).

\section{Oxidative stress theory of aging}

This theory posits that, during aerobic metabolism, the electron transport chain in mitochondria is not only a source of ATP, but also of reactive oxygen species (ROS). At moderate concentrations ROS may have important intracellular signalling functions, particular- ly for the control of ventilation, nerve transmission, and immune regulatory processes (Chung et al. 2006). ROS are also considered second messengers involved in activation of NF-kappa Beta via tumor necrosis factors (TNF) and interleukin-1 (Baud and Karin 2001), and in regulation of mitogen-activated protein kinase (MAPK) pathways (Sun and Oberley 1996). Through these actions, ROS affect cell function, growth and development and are therefore considered "absolutely essential for the regulation of the metabolome" (Linnane et al. 2007). Contrary to conventional wisdom, ROS are not produced in an unregulated manner, requiring immediate neutralization. Rather, rates of production are usually extremely low $\left[\sim 0.1 \mathrm{nM} \mathrm{H}_{2} \mathrm{O}_{2}\right.$ formed $\mathrm{min}^{-1} \mathrm{mg}^{-1}$ mitochondrial protein, $\sim 0.01 \%$ of metabolic rate (St-Pierre et al. 2002)]. High levels of ROS may be incompletely neutralized by antioxidants within the cell, resulting in indiscriminate damage to cellular constituents (lipids, proteins and DNA; Fig. 1). ROS levels may increase in damaged or aged mitochondria and cause accumulation of ROS beyond physiological levels.

Oxidative damage may be inadequately repaired or eliminated. This can lead to physiological deterioration and phenotypic changes in the elderly and increased incidence of age-related diseases and death, and thus may be a key determinant of maximum
Fig. 1 A schematic representation of the oxidative stress theory of aging as outlined by Harman (1956). The theory predicts that, as an inevitable byproduct of metabolic activity, reactive oxygen species (ROS) are produced. If these are not completely neutralized, oxidative damage to proteins, DNA and lipids may occur. Oxidized lipids are themselves potent ROS, autocatalyzing this process. Unrepaired damage accumulates and results in the typical aging phenotype

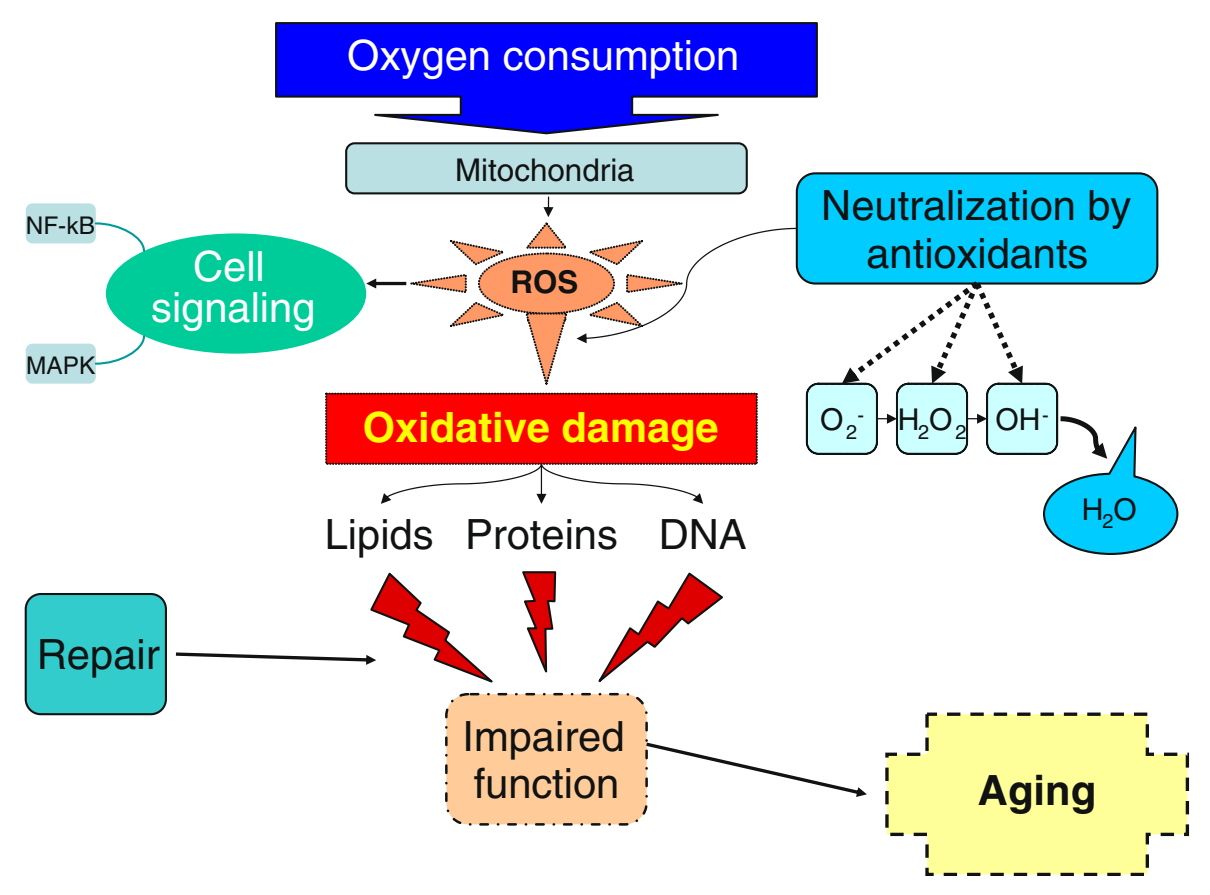


species lifespan (MLS). Oxidative stress may also provide a mechanism upon which other "damage" theories of aging are based. Examples include genomic instability as a result of DNA damage, and accumulation of glycated crosslinks during protein damage that can result in the pathogenesis associated with cardiovascular and neurodegenerative disease. ROS production plausibly fulfils the four key characteristics used in defining the aging process: ROS are endogenously produced under normal physiological conditions; they are produced continuously throughout life; and their deleterious effects on biological macromolecules may cause irreversible damage, especially in post-mitotic tissues. Given these circumstances, differential rates of aging among species may be due to differences in oxidative damage accrual, either in response to low rates of ROS production or through enhanced antioxidant defence. Despite the intuitive logic and vast support for this theory (Barja et al. 1994; Beckman and Ames 1998; Droge and Schipper 2007; Sohal et al. 2002) a causal link between oxidative stress and the rate of aging still has not been clearly established. Not all available data support the oxidative stress hypothesis, begging the question of whether or not this aging theory is, in fact, still valid (Kregel and Zhang 2007; Muller et al. 2007a; Sanz et al. 2006).

\section{Oxidative damage: a historical perspective}

Antoinne Lavoisier suggested in 1778 that oxygen was poisonous after noting that guinea pigs housed in pure oxygen died before the gas was used up (cited in Gilbert 1963). The rate of living theory of aging (Pearl 1928) originates with these findings, as well as studies on resting metabolic rate in various animal species (Rubner 1908). This theory asserted that lifetime oxygen consumption is rigidly fixed, therefore, metabolic rate determines longevity.

Free radicals were first regarded as the cause of oxygen toxicity in 1954 (Gerschman et al. 1954), and soon afterward Denham Harman integrated the "rate of living theory" with the "free radical theory of oxygen toxicity", proposing that aging is due to the harmful activities of free radicals endogenously formed during normal metabolic processes (Harman 1956). Since then, the free radical theory has been repeatedly modified, renamed, and constantly pro- pounded (Beckman and Ames 1998; Harman 1972; Hulbert 2005; Ishii 2007).

The oxidative stress and rate-of-living theories are iterations of the same hypothesis, if one supposes that higher levels of ROS are generated at faster metabolic rates than at lower metabolic rates (Hulbert et al. 2007; Speakman 2005a). Animals with high massspecific metabolic rates ought to have short lifespans, but this premise is not supported in all cases by published data (Hulbert et al. 2007; Speakman 2005a): (1) species lifetime energy expenditure based upon average daily metabolic rate is not constant, but rather declines by more than $20 \%$ for every doubling of body mass; (2) although dietary restriction extends lifespan, this process is not accompanied by attenuations in mass-specific metabolic rate (Hulbert et al. 2004); (3) significant species differences in MLS in both birds and mammals cannot be explained by divergent metabolic rates. Even within a species those individuals with the highest metabolic rates can live longest and those that exercise more do not necessarily have shorter lives (Speakman 2005b). Not surprisingly, therefore, the initial iteration of this theory, although still often proposed (Ishii 2007), is no longer considered plausible.

We have questioned whether data from nontraditional animal models for aging research offer support for the oxidative stress theory. We hypothesised that species that naturally live considerably longer than predicted by body size would (1) show lower rates of ROS production, (2) have a better antioxidant defence and (3) accrue less damage than shorter-lived counterparts. Surprisingly, there are only a handful of comparative studies that employ this approach and most of these have focused on rodents, bats or birds (Brunet-Rossinni and Austad 2004; Buffenstein et al. 2007; Pamplona et al. 1998; Pamplona et al. 2005; Perez-Campo et al. 1998).

\section{Do long-living animals produce less ROS than shorter-living animals?}

Complex I and complex III of the electron transport chain are the main sites of ROS production. Rates and sites of ROS production may be determined by manipulating substrates and chemical additives in preparations of isolated mitochondria. Despite an order of magnitude range in species longevity, ROS 
production at complex II, the ubiquinol pool, and complex III does not correlate with MLS of birds and mammals. Only when maximum generation of mitochondrial ROS is measured by using succinate as the substrate are species differences in ROS production observed that correlate with MLS.

Succinate oxidation results in an elevated proton motive force and the formation of a highly reduced ubiquinol pool that leads to reverse electron transport. This, in turn, reduces conversion of NAD to NADH, and leaks superoxide radicals into the mitochondrial matrix (Lambert et al. 2007). There is considerable debate regarding whether this "stalled" electron transport reflects a natural physiological state. ROS production on succinate substrates negatively correlated with MLS among a large group $(n=12)$ of diverse species including rodents, bats, baboons, birds and cattle, accounting for approximately $50 \%$ of the observed variability (Lambert et al. 2007). Because different laboratories have different ways of measuring ROS production and methodology seems to impact results, data from different studies cannot be combined but rather observed trends within a study must be compared. The data from Lambert et al. (2007) support now-classical studies (Ku and Sohal 1993) comparing hydrogen peroxide production in mitochondria from long-living pigeons and shorter-living rats. However, careful scrutiny of these data as well as those of a comparative study (Brunet-Rossinni 2004) among long-lived little brown bats (Myotis lucifugus; MLS 34 years), short-tailed shrews (Blarina brevicauda; 2 years) and white-footed mice (Peromyscus leuocopus; 8 years) are equivocal. In the latter study, mitochondria isolated from bat hearts showed 0.330.5 times the amount of ROS production of heart mitochondria from shorter-living species, although lower ROS production in bats did not correlate precisely with the 17- or 4-fold differences in MLS when compared to shrews and mice, respectively. Furthermore, ROS production in mitochondria isolated from little brown bat brains were considerably higher than that observed in brains of shorter-living whitefooted mice. In the larger 12-species study (Lambert et al. 2007), short-and long-lived bat species, whitefooted mice (Peromyscus leucopus), and wild derived (early generation) house mice (Mus musculus) all exhibited statistically similar levels of hydrogen peroxide production, as did C57BL6 laboratory mice and naked mole-rats (NMRs), despite a 9-fold differ- ence in longevity (Fig. 2). These non-significant differences in ROS levels in species with divergent longevity were, however, not strong enough to efface the general trend showing a correlation between reverse electron transport and MLS observed for all 12 species in that study (Fig. 2; Lambert et al. 2007).

It is possible that long-living NMRs, white-footed mice and the bat species studied to date employ "private mechanisms" (Martin et al. 1996) for slow aging that are independent of ROS production, or that measures of hydrogen peroxide do not accurately reflect ROS production. However, a lack of correlation between lifespan and ROS production also has been recently reported for Drosophila (Miwa et al. 2004). These are not the only exceptions to that predicted from the oxidative stress theory, although there are also many studies that do provide strong support for this theory. For instance, Ross (2000) reported that a long-lived line of Drosophila produce fewer free radicals when compared to a normal-lived line, in addition to demonstrating age-specific increases in ROS production in both lines with a concomitant age-specific decrease in aerobic efficiency. Collectively, these mixed findings should serve to caution against definitive and conclusive support for this theory: studies from a wider range of long-lived, similar sized, phylogenetically matched species are needed to resolve the role of ROS production as a determinant of longevity.

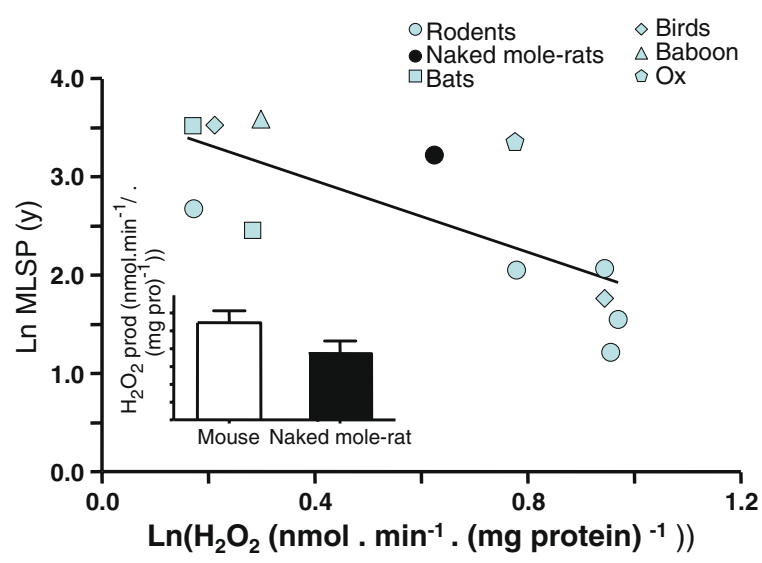

Fig. 2 Rates of ROS production in 12 species of birds and mammals with disparate longevities. Although species ROS production significantly correlates with longevity, significant differences fail to appear between specific similar-sized mammals, e.g., rodents (inset; NS not significant) and bats, with divergent longevity. Data in modified figure are taken from Lambert et al. (2007). Copyright permission was kindly granted by Wiley-Blackwell Publishing, Oxford, UK 


\section{Is antioxidant defense in long-living animals superior?}

Antioxidant activity as a determinant of MLS is controversial (Barja 2002a; Sohal and Weindruch 1996), with reports of positive, negative, or no correlation between antioxidant activity and lifespan (Andziak et al. 2005; Perez-Campo et al. 1998, 1993; Sohal et al. 1993; Wilhelm Filho et al. 2007). Indeed, in some comparative studies, longer-living species appear to have superior antioxidant defenses for efficiently mopping up and neutralizing ROS; in other studies, longer-lived species show similar or even lower levels of both enzymatic and nonenzymatic antioxidant activities (Fig. 3) than do shorter-living species (Wilhelm Filho et al. 2007). In the case of the longest-living rodent, NMR, catalase (CAT) activity is similar to mice, $\mathrm{Cu} / \mathrm{Zn}$ superoxide dismutase $(\mathrm{Cu} / \mathrm{ZnSOD})$ is slightly higher, whereas glutathione peroxidase is 70 -fold lower (Andziak et al. 2005). An often-touted explanation for the negative correlation between antioxidant activities and species longevity is that enhanced antioxidant defenses are not the reason for extended longevity of long-living mammals, but rather that lower antioxidant levels in longer-living species may be indicative of lower levels of oxidative stress (Barja 2002b, 2007; Ferreira-Cravo et al. 2007; Pamplona and Barja 2007; Sanz et al. 2006). Ironically, animals in dormant, hypometabolic states (e.g., hibernation or torpor) of low ROS production tend to have high levels of antioxidants (Hermes-Lima and ZentenoSavin 2002) whereas those in hypermetabolic states (i.e., during arousal from hibernation or activity) often do not (Eddy et al. 2005; Hermes-Lima et al. 1998; Osborne and Hashimoto 2006; Storey 2004). These conflicting findings may reflect the fact that antioxidants are in a continuous, presumably adaptive state of flux. Also, antioxidant defense systems are likely to be highly complex, involving many different antioxidants and multiple layers of interaction. Many novel antioxidants continue to be identified and, at this stage, we do not have a solid understanding of the degree of redundancy, nor how the various components of this expansive antioxidant "orchestra" work together. Just measuring the activity of a few wellstudied key antioxidants may not tell the whole story. An alternative explanation for the ambiguous findings to date is that antioxidants are simply not integral determinants of longevity.

In many species, aging results in reduced antioxidant capacity and leads to a progressive decline in biochemical defenses. In others, more antioxidants are produced in the elderly, ostensibly to neutralize age-

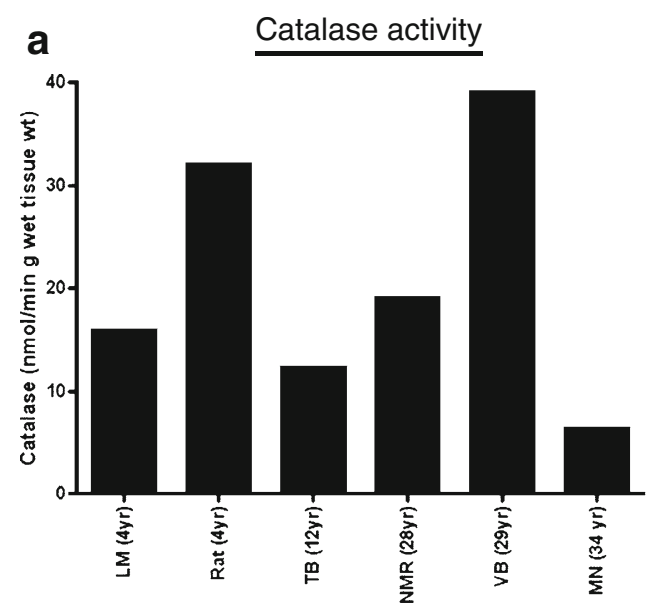

Fig. 3 Bat and rodent catalase (a) and protein carbonyl (b) levels do not correlate with maximum species lifespan (MLS). LM Laboratory mouse (Mus musculus; 4 years) or rat (Rattus norvegicus; 4 years), AGS arctic ground squirrel (Spermophilus parryii; 11 years), VB vampire bat (Desmodus rotundus; 29 years), GP guinea pig (Cavia porcellus; 12 years), DMR damara mole-rat (Fukomys damarensis; 18 years), NMR naked mole-rat (Heterocephalus glaber; >28.3 years), MFT Mexican

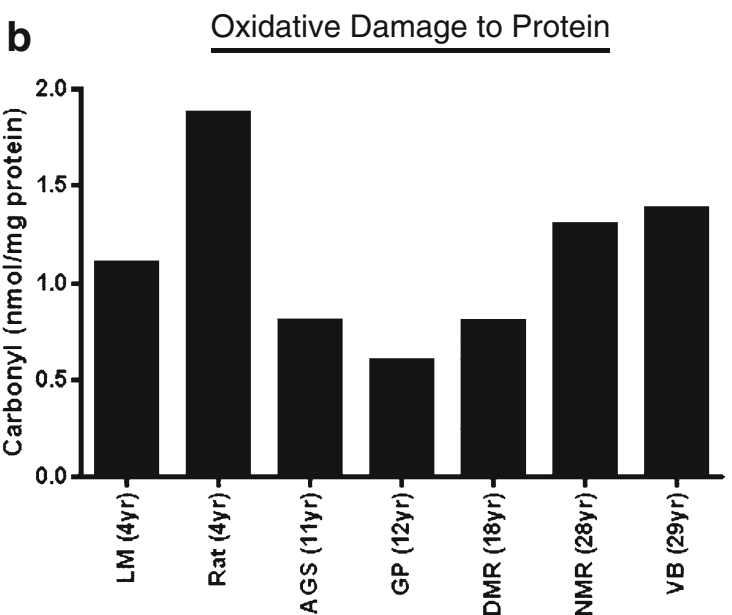

free-tailed bat (Tadarida brasiliensis; 12 years), LBB little brown bat (Myotis lucifugus; 34 years). Data sources for catalase and protein carbonyl levels: Andziak et al. 2005; Ferreira-Cravo et al. 2007; Hermes-Lima et al. 2007; Wilhelm Filho et al. 2007; R. Buffenstein et al. unpublished data. Lifespan data are from Buffenstein 2005 and unpublished data for $F$. damarensis; http://genomics.senescence.info and http:// www.blueplanetbiomes.org/arctic_ground_squirrel.htm 
related increases in ROS production by malfunctioning mitochondria (Linnane et al. 2007; Sanz et al. 2006). One of the big problems in measuring antioxidant activities is the assumption that "more is better," and that higher levels of antioxidants will equate with reduced oxidative stress (Rando and Epstein 1999). Despite many years of study of the potential of pharmacological supplementation of traditional antioxidants as an "anti-aging" therapy, there is no well-authenticated study that unequivocally demonstrates a benefit of antioxidant supplementation in mammals (de Grey 2000; Linnane et al. 2007; Sanz et al. 2006). Indeed, dietary supplementation of antioxidants appears to extend lifespan only when survival of control groups was suboptimal. Moreover, antioxidant supplementation has not extended lifespan beyond the MLS determined for any species (Hulbert et al. 2007). These results suggest that while antioxidant dietary supplements can protect against increased oxidative stress from exogenous sources or pathological conditions, they have no effect upon aging rate.

Technical advances in functional genomics have facilitated in vivo modulation of antioxidant expression. In yeast, genetic deletions or overexpression of SOD unambiguously affect lifespan (Fabrizio et al. 2004). Contradictory findings have, however, been reported in Caenorhabditis elegans. Melov et al. (2000) showed lifespan extension with SOD/CAT mimetics, whereas Keaney et al. (2004) confirmed that SOD mimetics increased SOD activity in vivo, but found no change in lifespan. The plethora of studies undertaken in fruit flies has also yielded inconsistent findings (for review, see Muller et al. 2007a), and no consensus has been reached whether antioxidant over-expression in invertebrates extends lifespan. Other work has shown that over-expression of SOD may be harmful and lead to more oxidative damage (Rando and Epstein 1999). Studies in mice have also yielded inconsistent results (Table 1). For example, transgenic mice overexpressing catalase showed the entire spectrum of responses: (1) a substantial increase in lifespan (Schriner et al. 2005), (2) no change in lifespan (Chen et al. 2004; Huang et al. 2000), or (3) were more vulnerable to oxidative insults (Chen et al. 2004). Overexpression of $\mathrm{Cu} / \mathrm{Zn}$ SOD in several studies did not influence lifespan (Hulbert et al. 2007; Muller et al. 2007b). Furthermore, heterozygous knockouts for MnSOD, while showing reduced enzyme activity, have a similar lifespan to that exhibited by wild-type mice, even though oxidative damage in several tissues (e.g., 8oxodG in liver, heart, brain, spleen) is significantly elevated (Van Remmen et al. 2003).

This inability of increased antioxidant enzyme activity to attenuate lifespan despite augmented oxidative damage is particularly problematic for the oxidative stress theory of aging. The absence of a decline in lifespan, even when accompanied by pronounced increases in oxidative damage, suggests that a decline in antioxidant activity and the accompanying increases in oxidative damage play no role in lifespan determination. While they may merely indicate that aging is a multifaceted process and other factors also influence lifespan, these data nonetheless refute a key tenet of the oxidative stress theory.

Table 1 Changes in lifespan and phenotype, including oxidative damage (OD), with genetic modification of expression of the antioxidants catalase (CAT) and superoxide dismutase (SOD) and of methionine sulfoxide reductase (MrsA) in mice

\begin{tabular}{|c|c|c|c|}
\hline Genetic manipulation & Phenotype & Lifespan & Source \\
\hline \multicolumn{4}{|l|}{ Overexpression } \\
\hline Mitochondrial CAT & Delayed aging & $10-20 \%$ increase & Schriner et al. 2005 \\
\hline Nuclei CAT & Normal & None & Schriner et al. 2000 \\
\hline $\mathrm{Cu} / \mathrm{Zn} \mathrm{SOD}$ & Multiple pathology & None & $\begin{array}{l}\text { Huang et al. 2000; } \\
\text { Rando and Epstein } 1999\end{array}$ \\
\hline Mn SOD & Multiple pathology & None & Raineri et al. 2001 \\
\hline \multicolumn{4}{|l|}{ Knockout } \\
\hline $\mathrm{MnSOD}^{-/-}$ & Multiple pathology & Decrease & Muller et al. 2007b \\
\hline CAT & Multiple pathology & None & Muller et al. 2007b \\
\hline $\mathrm{Cu} / \mathrm{Zn} \mathrm{SOD}{ }^{-/-}$ & Multiple pathology & $30 \%$ Decrease & Elchuri et al. 2005 \\
\hline $\mathrm{Mn} \mathrm{SOD}^{-/-}$ & Increased OD & None & Van Remmen et al. 2003 \\
\hline $\mathrm{MrsA}^{-/-}$ & Increased OD & $40 \%$ Decrease & Moskovitz et al. 2001 \\
\hline
\end{tabular}


Is oxidative stress lower in young long-living animals than in young shorter-living animals?

Although early life influences like nutrition, toxins and growth factors can set the stage for aging patterns, biological capacities that allow slow aging should be expected to persist throughout life, since the only way to attain longevity is to employ mechanisms that maintain low age-specific mortality throughout life. For example, the ratio of intracellular reduced and disulfide forms of glutathione (GSH/ GSSG) is often used as an indicator of cellular redox state, degree of oxidative stress and the antioxidant capacity of cells (Griffith 1999). The oxidative stress theory posits that this ratio ought to be attenuated in long-living species. But studies of GSH/GSSG ratios reveal that long-lived NMRs, vampire bats and nonhibernating squirrels have a more pro-oxidative cellular environment than shorter-living mice and rats (Ferreira-Cravo et al. 2007; Hermes-Lima et al. 2007; Yang et al. 2007). Indeed, there is no correlation between GSH/GSSG ratios in young individuals and MLS in a wide variety of species.

\section{Do levels of oxidative damage correlate with MLS?}

There have been many reports that accrued oxidative damage increases substantially with age (Beckman and Ames 1998) and is commonly associated with age-related pathology. However, results are contingent on the species or specific tissues assayed and in many cases this relationship has not been found (Palomero et al. 2001). This lack of consensus has led some to conclude that progressive accrual of oxidative damage is not an integral component of organismal aging, but rather that species-specific steady state levels of oxidative damage are important determinants of aging (Rikans and Hornbrook 1997).

Some comparative studies show an inverse relationship between oxidative damage and longevity, already evident in young adults of a species (Pamplona et al. 1999). While data from many longer-living species across a wide range of phyla concur with predictions based on this theory (Barja 2002b), exceptions have been reported; for example within flies, the longer-lived Drosophila spp. has more protein carbonyls than the shorter-lived blow flies (Calliphora vicina; Sohal et al. 1995). Similarly, both long-lived NMRs and bats have higher levels of protein carbonyls than short-lived mice and rats when carbonyls are measured using identical techniques (Fig. 3b), and levels of oxidative damage in those four mammal species does not vary inversely with lifespan. High levels of oxidative damage in both longliving vampire bats and NMRs has been attributed to their high intracellular iron content (Buffenstein 2005; Ferreira-Cravo et al. 2007; R. Cheung, T. Yang and R. Buffenstein, unpublished data). High levels of oxidative DNA damage also have also been observed in long-living birds (Hamilton et al. 2001). Collectively, these data from phylogenetically divergent species in different vertebrate classes differ from predictions of the oxidative stress theory of aging. These and other exceptions to this paradigm are often glossed over, buried in the results sections of papers, never published, or apologetically discussed while the authors try and find some way to interpret datausually as a quirky "private mechanisms" that may still vaguely support the theory.

Comparative studies at variance with the oxidative stress theory generally are dismissed. Often it is suggested that longevity records may be erroneous, based upon too few species or simply attributed to poor record keeping. Similarly, housing conditions may induce higher levels of oxidative damage than naturally encountered.

Perhaps one of the strongest challenges to the oxidative stress theory comes from studies of oxidative damage in transgenic laboratory mice. Transgenic heterozygous mice in which mitochondrial SOD activity is compromised show high levels of oxidative damage without any deleterious effect on lifespan (Van Remmen et al. 2003). Many factors have the potential to shorten lifespan without necessarily revealing insights into the aging process. Nonetheless, these findings, like those showing high steady-state levels of oxidative damage in NMRs and bats, considered in light of the lack of correlation between oxidative stress or accrued oxidative damage with lifespan, strengthen the argument that oxidants may not be the key determinants of aging. While oxidative damage may indeed be a by-product of aging, other mechanisms, such as specific cell and molecular properties (e.g., DNA integrity, protein stability, and epigenetics) and their concomitant influences on cell signaling pathways and gene regulation, seem more likely to serve as pacemakers of the aging process. 
Multi-species studies and transgenic studies of whole-cell responses to oxidative and chemical insults do provide some support for the oxidative stress theory of aging (Ogburn et al. 1998, 2001; Mele et al. 2006; Harper et al. 2006; Kapahi et al. 1999; Salmon et al. 2005; 2008). Fibroblasts from long-living mammals and birds have shown considerable resistance to oxidative stressors (e.g., paraquat and cadmium), requiring higher doses of oxidative insult to kill $50 \%$ of the cells (Ogburn et al. 1998, 2001; Harper et al. 2006; Kapahi et al. 1999; Salmon et al. 2005; 2008). Cell membrane composition may be an important component of this cellular oxidative resistance (Mitchell et al. 2007). Membrane polyunsaturated fatty acid composition varies in a predictable manner with species lifespan, and this may influence peroxidation susceptibility as well as membrane permeability (Hulbert et al. 2006).

Fibroblasts from both NMRs and long-lived dwarf mice are more sensitive to drugs that disrupted the function of the endoplasmic reticulum and protein degradation pathways than cells from shorter-lived animals (Salmon et al. 2008). These findings suggest that slow-aging species may employ exquisitely sensitive biodegradation and repair pathways in vulnerable tissues, yet also be tolerant of oxidative damage in others. We previously showed that certain proteins in NMR tissues carry the brunt of oxidative damage (Andziak et al. 2006). One of these proteins has been identified as triosphosphate isomerase, an important glycolytic enzyme. Despite extremely high levels of damage in NMR cells, activity of this enzyme is not compromised. It is not known why species regulate sustained amounts of damage at different levels, but most likely this reflects the evolution of tradeoffs between costs and benefits associated with damage accrual and repair.

Although NMR acquire more oxidative damage at a young age (2 years) than physiologically agematched (7\% MLS $\sim 4$ months) shorter-lived rodents, they appear tolerant of this level of damage and maintain these levels of damage at a steady state over a 20-year period. Based upon the lack of additional age-related damage accumulation shown in NMRs, we infer that efficient repair processes allow NMRs to maintain the same, albeit high, steady state levels of oxidative damage acquired during the first 2 years of life. Lack of age-related increase in oxidative damage provides some peripheral support for the oxidative stress theory of aging. Enhanced macroautophagy, lysosomal degradation and proteosome activity occur with caloric-restriction (CR)-induced lifespan extension (Bergamini et al. 2003), and also may play an integral role in the prolonged healthy lifespan of slow-aging organisms. This is yet to be investigated; however, there is some evidence that the role of oxidative stress in slow, successful aging is secondary to that of enhanced autophagic degradation and efficient regulation of apoptosis and repair. Once activated, repair processes may facilitate the maintenance of steady-state levels of damage below a critical threshold where functionality is impaired, and thereby enable slow and successful aging.

\section{Conclusions}

Given the many exceptions to straightforward predictions of the oxidative stress theory of aging we cannot categorically accept that aging results simply from an imbalance between ROS production, antioxidant defense and damage accrual. While, if left unchecked, ROS may cause life-threatening pathology, there is no conclusive evidence that under normal conditions oxidative damage directly limits lifespan. In some long-living mammals, high levels of oxidative damage accumulate at a young age (Andziak and Buffenstein 2006) with no ill effects. Similarly, in short lived mice, even if antioxidants were experimentally depleted and oxidative damage increased there is no associated change in lifespan (Van Remmen et al. 2003). These results strongly suggest that longevity is unrelated to any of the diverse range of oxidative stress parameters currently being measured.

In summary, considerable data now exist to challenge the embattled oxidative stress theory. Indeed, research into aging would be better served if we stopped ignoring data that do not support this theory. Instead, we suggest that this august mechanistic theory of aging be reexamined in light of a plethora of contradictory data, and alternative mechanisms influencing aging (such as autophagy, genomic and protein stability) be further investigated.

Acknowledgments Our work is supported by grants from the NIH/NIA, Ellison Foundation and the Paul Glenn Foundation to R.B. We apologize to those whose works were not cited through inadvertent omission or because of space limitations. 


\section{References}

Andziak B, Buffenstein R (2006) Disparate patterns of agerelated changes in lipid peroxidation in long-lived naked mole-rats and shorter-lived mice. Aging Cell 5:525-532

Andziak B, O'Connor TP, Buffenstein R (2005) Antioxidants do not explain the disparate longevity between mice and the longest-living rodent, the naked mole-rat. Mech Ageing Dev 126:1206-1212

Andziak B, O'Connor TP, Qi WB, DeWaal EM, Pierce A, Chaudhuri AR, Van Remmen H, Buffenstein R (2006) High oxidative damage levels in the longest-living rodent, the naked mole-rat. Aging Cell 5:463-471

Barja G (2002a) Endogenous oxidative stress: relationship to aging, longevity and caloric restriction. Ageing Res Rev $1: 397-411$

Barja G (2002b) Rate of generation of oxidative stress-related damage and animal longevity. Free Radic Biol Med 33:1167-1172

Barja G (2007) Mitochondrial oxygen consumption and reactive oxygen species production are independently modulated: implications for aging studies. Rejuvenation Res 10:215-223

Barja G, Cadenas S, Rojas C, Lopez-Torres M, Perez-Campo R (1994) A decrease of free-radical production near-critical targets as a cause of maximum longevity in animals. Comp Biochem Physiol Biochem Mol Biol 108:501-512

Bartke A (2008) New findings in gene knockout, mutant and transgenic mice. Exp Gerontol 43:11-14

Baud V, Karin M (2001) Signal transduction by tumor necrosis factor and its relatives. Trends Cell Biol 11:372-377

Beckman KB, Ames BN (1998) The free radical theory of aging matures. Physiol Rev 78:547-581

Bergamini E, Cavallini G, Donati A, Gori Z (2003) The antiageing effects of caloric restriction may involve stimulation of macroautophagy and lysosomal degradation, and can be intensified pharmacologically. Biomed Pharmacother 57:203-208

Brunet-Rossinni AK (2004) Reduced free-radical production and extreme longevity in the little brown bat (Myotis lucifugus) versus two non-flying mammals. Mech Ageing Dev 125:11-20

Brunet-Rossinni AK, Austad SN (2004) Ageing studies on bats: a review. Biogerontology 5:211-222

Buffenstein R (2005) The naked mole-rat; a new long-living model for human aging research. J Gerontol Biol Sci 60:1369-1377

Buffenstein R, Edrey YH, Larsen PL (2007) Animal models in aging research: a critical examination. In: Conn PM (ed) Source Book of Models for Biomedical Research. Humana, Totowa, NJ, pp 499-506

Chen X, Liang H, Van Remmen H, Vijg J, Richardson A (2004) Catalase transgenic mice: characterization and sensitivity to oxidative stress. Arch Biochem Biophys 422:197-210

Chung HY, Sung B, Jung KJ, Zou Y, Yu BP (2006) The molecular inflammatory process in aging. Antioxid Redox Signal 8:572-581

de Grey ADNJ (2000) The non-correlation between maximum longevity and enzymatic antioxidant levels among homeo- therms: Implications for retarding human aging. J AntiAging Med 3:25-36

Droge W, Schipper HM (2007) Oxidative stress and aberrant signaling in aging and cognitive decline. Aging Cell $6: 361-370$

Eddy SF, McNally JD, Storey KB (2005) Up-regulation of a thioredoxin peroxidase-like protein, proliferation-associated gene, in hibernating bats. Arch Biochem Biophysics 435:103-111

Elchuri S, Oberley TD, Qi W, Eisenstein RS, Jackson Roberts L, Van Remmen H, Epstein CJ, Huang TT (2005) CuZnSOD deficiency leads to persistent and widespread oxidative damage and hepatocarcinogenesis later in life. Oncogene 24:367-380

Fabrizio P, Battistella L, Vardavas R, Gattazzo C, Liou LL, Diaspro A, Dossen JW, Gralla EB, Longo VD (2004) Superoxide is a mediator of an altruistic aging program in Saccharomyces cerevisiae. J Cell Biol 166:1055-1067

Ferreira-Cravo M, Welker AF, Andrade RG, Drew K, HermesLima M (2007) Physiological oxidative stress in the animal world. Comp Biochem Physiol Mol Integ Physiol 148:S63-S64

Finch CE, Ruvkun G (2001) The genetics of aging. Annu Rev Genomics Hum Genet 2:435-462

Gerschman R, Gilbert DL, Nye W, Dwyer P, Fenn WO (1954) Oxygen poisoning and $\mathrm{x}$-irradiation-a mechanism in common. Science 119:623-626

Gilbert D (1963) The role of pro-oxidants and antioxidants in oxygen toxicity. Radiat Res 3S:44-53

Griffith OW (1999) Biologic and pharmacologic regulation of mammalian glutathione synthesis. Free Radic Biol Med 27:922-935

Hamilton ML, Van Remmen H, Drake JA, Yang H, Guo ZM, Kewitt K, Walter CA, Richardson A (2001) Does oxidative damage to DNA increase with age? Proc Natl Acad Sci USA 98:10469-10474

Harman D (1956) Aging - a theory based on free-radical and radiation-chemistry. J Gerontol 11:298-300

Harman D (1972) Free-radical theory of aging-dietary implications. Am J Clin Nutr 25:839-843

Harper JM, Salmon AB, Chang Y, Bonkowski M, Bartke A, Miller RA (2006) Stress resistance and aging: influence of genes and nutrition. Mech Ageing Dev 127:687-694

Hermes-Lima M, Zenteno-Savin T (2002) Animal response to drastic changes in oxygen availability and physiological oxidative stress. Comp Biochem Physiol C Toxicol Pharmacol 133:537-556

Hermes-Lima M, Storey JM, Storey KB (1998) Antioxidant defenses and metabolic depression. The hypothesis of preparation for oxidative stress in land snails. Comp Biochem Physiol B Biochem Mol Biol 120:437-448

Hermes-Lima M, Welker AF, Ferreira-Cravo M, Campos EG (2007) Physiological oxidative stress and low oxygen. Comp Bioche Physiol B Mol Integr Physiol 148:S60S60

Huang TT, Carlson EJ, Gillespie AM, Shi Y, Epstein CJ (2000) Ubiquitous overexpression of $\mathrm{CuZn}$ superoxide dismutase does not extend life span in mice. J Gerontol A Biol Sci Med Sci 55:B5-B9

Hulbert AJ (2005) On the importance of fatty acid composition of membranes for aging. J Theor Biol 234:277-288 
Hulbert AJ, Clancy DJ, Mair W, Braeckman BP, Gems D, Partridge L (2004) Metabolic rate is not reduced by dietary-restriction or by lowered insulin/IGF-1 signalling and is not correlated with individual lifespan in Drosophila melanogaster. Exp Gerontol 39:1137-1143

Hulbert AJ, Faulks S, Buffenstein R (2006) Oxidation-resistant membrane phospholipids can explain longevity differences among the longest-living rodents and similarly-sized mice. J Gerontol A Biol Sci Med Sci. 61:1009-1018

Hulbert AJ, Pamplona R, Buffenstein R, Buttemer WA (2007) Life and death: Metabolic rate, membrane composition, and life span of animals. Physiol Rev 87:175-1213

Ishii N (2007) Role of oxidative stress from mitochondria on aging and cancer. Cornea 26:S3-S9

Kapahi P, Boulton ME, Kirkwood TB (1999) Positive correlation between mammalian life span and cellular resistance to stress. Free Radic Biol Med 26:495-500

Keaney M, Matthijssens F, Sharpe M, Vanfleteren J, Gems D (2004) Superoxide dismutase mimetics elevate superoxide dismutase activity in vivo but do not retard aging in the nematode Caenorhabditis elegans. Free Radic Biol Med 37:239-250

Kregel KC, Zhang HJ (2007) An integrated view of oxidative stress in aging: basic mechanisms, functional effects, and pathological considerations. Am J Physiol Regul Integr Comp Physiol 292:R18-R36

$\mathrm{Ku} \mathrm{HH}$, Sohal RS (1993) Comparison of mitochondrial prooxidant generation and antioxidant defenses between rat and pigeon-possible basis of variation in longevity and metabolic potential. Mech Ageing Dev 72:67-76

Lambert AJ, Boysen HM, Buckingham JA, Yang T, Podlutsky A, Austad SN, Kunz TH, Buffenstein R, Brand MD (2007) Low rates of hydrogen peroxide production by isolated heart mitochondria associate with long maximum lifespan in vertebrate homeotherms. Aging Cell 6:607-618

Linnane AW, Kios M, Vitetta L (2007) Healthy aging: regulation of the metabolome by cellular redox modulation and prooxidant signaling systems: the essential roles of superoxide anion and hydrogen peroxide. Biogerontology $8: 445-467$

Martin GM, Austad SN, Johnson TE (1996) Genetic analysis of ageing: role of oxidative damage and environmental stresses. Nat Genet 13:25-34

Mele J, Van Remmen H, Vijg J, Richardson A (2006) Characterization of transgenic mice that overexpress both copper zinc superoxide dismutase and catalase. Antioxid Redox Signal 8:628-638

Melov S, Ravenscroft J, Malik S, Gill MS, Walker DW, Clayton PE, Wallace DC, Malfroy B, Doctrow SR, Lithgow GJ (2000) Extension of life-span with superoxide dismutase/catalase mimetics. Science 289:1567-1569

Mitchell TW, Buffenstein R, Hulbert AJ (2007) Membrane phospholipid composition may contribute to exceptional longevity of the naked mole-rat (Heterocephalus glaber): a comparative study using shotgun lipidomics. Exp Gerontol. 42:1053-1062

Miwa S, Riyahi K, Partridge L, Brand MD (2004) Lack of correlation between mitochondrial reactive oxygen species production and life span in Drosophila, strategies for engineered negligible senescence: why genuine control of aging may be foreseeable. Ann N Y Acad Sci 1019:388-391
Moskovitz J, Bar-Noy S, Williams WM, Requena J, Berlett BS, Stadtman ER (2001) Methionine sulfoxide reductase (MsrA) is a regulator of antioxidant defense and lifespan in mammals. Proc Natl Acad Sci USA 98:12920-12925

Muller FL, Lustgarten MS, Jang Y, Richardson A, Van Remmen H (2007a) Trends in oxidative aging theories. Free Radic Biol Med 43:477-503

Muller FL, Song W, Jang YC, Liu Y, Sabia M, Richardson A, Van Remmen H (2007b) Denervation-induced skeletal muscle atrophy is associated with increased mitochondrial ROS production. Am J Physiol Regul Integr Comp Physiol 293:R1159-R1168

Ogburn CE, Austad SN, Holmes DJ, Kiklevich JV, Gollahon K, Rabinovitch PS, Martin GM (1998) Cultured renal epithelial cells from birds and mice: enhanced resistance of avian cells to oxidative stress and DNA damage. J Gerontol A Biol Sci Med Sci 53:B287-B292

Ogburn CE, Carlberg K, Ottinger MA, Holmes DJ, Martin GM, Austad SN (2001) Exceptional cellular resistance to oxidative damage in long-lived birds requires active gene expression. J Gerontol A Biol Sci Med Sci 56: B468-B474

Osborne PG, Hashimoto M (2006) Brain antioxidant levels in hamsters during hibernation, arousal and cenothermia. Behav Brain Res 168:208-214

Palomero J, Galan AI, Munoz ME, Tunon MJ, GonzalezGallego J, Jimenez R (2001) Effects of aging on the susceptibility to the toxic effects of cyclosporin A in rats. Changes in liver glutathione and antioxidant enzymes. Free Radic Biol Med 30:836-845

Pamplona R, Barja G (2007) Highly resistant macromolecular components and low rate of generation of endogenous damage: two key traits of longevity. Ageing Res Rev 6:189-210

Pamplona R, Portero-Otin M, Riba D, Ledo F, Gredilla R, Herrero A, Barja G (1999) Heart fatty acid unsaturation and lipid peroxidation, and aging rate, are lower in the canary and the parakeet than in the mouse. Z Geront Geriatr 32:231-231

Pamplona R, Portero-Otin M, Riba D, Lopez-Torres M, Barja G (1998) Relationship between fatty acid unsaturation, sensitivity to lipid peroxidation, and maximum life span in the liver of mammals, towards prolongation of the healthy life span. Ann N Y Acad Sci 854:516-516

Pamplona R, Portero-Otin M, Sanz A, Ayala V, Vasileva E, Barja G (2005) Protein and lipid oxidative damage and complex I content are lower in the brain of budgerigar and canaries than in mice. Relation to aging rate. AGE 27:267-280

Pearl R (1928) The rate of living. Knopf, New York

Perez-Campo R, Lopez-Torres M, Rojas C, Cadenas S, Barja G (1993) A comparative-study of free radicals in vertebrates. I. Antioxidant enzymes. Comp Biochem Physiol B Biochem Mol Biol 105:749-755

Perez-Campo R, Lopez-Torres M, Cadenas S, Rojas C, Barja G (1998) The rate of free radical production as a determinant of the rate of aging: evidence from the comparative approach. J Comp Physiol B 168:149-158

Raineri I, Carlson EJ, Gacayan R, Carra S, Oberley TD, Huang TT, Epstein CJ (2001) Strain-dependent high-level expression of a transgene for manganese superoxide 
dismutase is associated with growth retardation and decreased fertility. Free Radic Biol Med 31:1018-30

Rando TA, Epstein CJ (1999) Copper/zinc superoxide dismutase: more is not necessarily better! Ann Neurol 46:135-136

Rikans LE, Hornbrook KR (1997) Lipid peroxidation, antioxidant protection and aging. Biochim Biophys Acta 1362:116-127

Ross RE (2000) Age-specific decrease in aerobic efficiency associated with increase in oxygen free radical production in Drosophila melanogaster. J Insect Physiol 46:1477-1480

Rubner M (1908) Das Problem der Lebensdauer. Oldenburg, Munich

Salmon AB, Murakami S, Bartke A, Kopchick J, Yasumura K, Miller RA (2005) Fibroblast cell lines from young adult mice of long-lived mutant strains are resistant to multiple forms of stress. Am J Physiol Endocrinol Metab 289: E23-E29

Salmon AB, Akha AA, Buffenstein R, Miller RA (2008) Fibroblasts from naked mole-rats are resistant to multiple forms of cell injury, but sensitive to peroxide, ultraviolet light, and endoplasmic reticulum stress. J Gerontol A Biol Sci Med Sci 63(3):232-241 Mar

Sanz A, Pamplona R, Barja G (2006) Is the mitochondrial free radical theory of aging intact? Antioxid Redox Signal 8:582-599

Schriner SE, Smith AC, Dang NH, Fukuchi K, Martin GM (2000) Overexpression of wild-type and nuclear-targeted catalase modulates resistance to oxidative stress but does not alter spontaneous mutant frequencies at APRT. Mutat Res 449:21-31

Schriner SE, Linford NJ, Martin GM, Treuting P, Ogburn CE, Emond M, Coskun PE, Ladiges W, Wolf N, Van Remmen H, Wallace DC, Rabinovitch PS (2005) Extension of murine life span by overexpression of catalase targeted to mitochondria. Science 308:1909-1911

Sohal RS, Weindruch R (1996) Oxidative stress, caloric restriction, and aging. Science 273:59-63
Sohal RS, Agarwal S, Dubey A, Orr WC (1993) Protein oxidative damage is associated with life expectancy of houseflies. Proc Natl Acad Sci USA 90:7255-7259

Sohal RS, Sohal BH, Orr WC (1995) Mitochondrial superoxide and hydrogen-peroxide generation, protein oxidative damage, and longevity in different species of flies. Free Radic Biol Med 19:499-504

Sohal RS, Mockett RJ, Orr WC (2002) Mechanisms of aging: an appraisal of the oxidative stress hypothesis. Free Radic Biol Med 33:575-586

Speakman JR (2005a) Body size, energy metabolism and lifespan. J Exp Biol 208:1717-1730

Speakman JR (2005b) Correlations between physiology and lifespan - two widely ignored problems with comparative studies. Aging Cell 4:167-175

Storey KB (2004) Cold ischemic organ preservation: lessons from natural systems. Journal Investig Med 52: 315-322

St-Pierre J, Buckingham JA, Roebuck SJ, Brand MD (2002) Topology of superoxide production from different sites in the mitochondrial electron transport chain. J Biol Chem 277:44784-44790

Strehler BL (1962) Time, cells and aging. Academic, New York

Sun Y, Oberley LW (1996) Redox regulation of transcriptional activators. Free Radic Biol Med 21:335-348

Van Remmen H, Ikeno Y, Hamilton M, Pahlavani M, Wolf N, Thorpe SR, Alderson NL, Baynes JW, Epstein CJ, Huang TT, Nelson J, Strong R, Richardson A (2003) Life-long reduction in MnSOD activity results in increased DNA damage and higher incidence of cancer but does not accelerate aging. Physiol Genomics 16:29-37

Wilhelm Filho D, Althoff SL, Dafre AL, Boveris A (2007) Antioxidant defenses, longevity and ecophysiology of South American bats. Comp Biochem Physiol C Toxicol Pharmacol 146:214-220

Yang T, Andziak B, Buffenstein R (2007) Rodent longevity is not directly associated with glutathione cycle. FASEB J 21:A821-A821 